\title{
El encuentro de Iglesias evangélicas indígenas con Iglesias «nacionales» y sus repercusiones político- religiosas en el Alto Río Negro (Amazonas, Brasil)
}

La rencontre d'Églises évangéliques indigènes avec des Églises «nationales » et ses répercussions politico-religieuses dans le Haut Rio Negro (Amazonas, Brésil) The encounter of indigenous evangelical churches with "national" churches and their political-religious repercussions en the upper Río Negro (Amazonas, Brazil)

\section{Élise Capredon}

\section{(2) OpenEdition}

Journals

Edición electrónica

URL: http://journals.openedition.org/bifea/10095

DOI: 10.4000/bifea.10095

ISSN: 2076-5827

Editor

Institut Français d'Études Andines

Edición impresa

Fecha de publicación: 8 diciembre 2018

Paginación: 227-246

ISSN: 0303-7495

Referencia electrónica

Élise Capredon, «El encuentro de Iglesias evangélicas indígenas con Iglesias «nacionales» y sus repercusiones político-religiosas en el Alto Río Negro (Amazonas, Brasil) », Bulletin de I'Institut français d'études andines [En línea], 47 (3) | 2018, Publicado el 08 diciembre 2018, consultado el 04 noviembre 2020. URL : http://journals.openedition.org/bifea/10095; DOI : https://doi.org/10.4000/bifea.10095

Les contenus du Bulletin de l'Institut français d'études andines sont mis à disposition selon les termes de la licence Creative Commons Attribution - Pas d'Utilisation Commerciale - Pas de Modification 4.0 International. 


\title{
El encuentro de Iglesias evangélicas indígenas con Iglesias «nacionales» y sus repercusiones político-religiosas en el Alto Río Negro (Amazonas, Brasil)
}

\author{
Élise Capredon*
}

\begin{abstract}
Resumen
Los estudios antropológicos que abordan las relaciones de los indígenas de la Amazonía con el cristianismo suelen resaltar el carácter efímero de las conversiones amerindias. Sin embargo, desde la segunda mitad del siglo XX, varios movimientos evangélicos indígenas han florecido en el área amazónica bajo la influencia de misioneros extranjeros. El artículo explora este fenómeno a partir del estudio de caso de los baniwa, un grupo de la Amazonía brasileña cuyos miembros crearon sus propias Iglesias. Al analizar la trayectoria de este movimiento religioso, se muestra que su encuentro con las Iglesias evangélicas nacionales favorece actualmente su institucionalización y articulación a movimientos similares, a nivel panétnico y transnacional.
\end{abstract}

Palabras clave: Amazonía, Brasil, baniwa, movimientos evangélicos, Iglesias indígenas, institucionalización

\section{La rencontre d'Églises évangéliques indigènes avec des Églises «nationales » et ses répercussions politico-religieuses dans le Haut Rio Negro (Amazonas, Brésil)}

\section{Résumé}

Les études anthropologiques qui abordent les relations des indiens de l'Amazonie avec le christianisme soulignent généralement le caractère éphémère des conversions amérindiennes. Toutefois, depuis la

Posdoctoranda beneficiada con la beca del Legs Lelong (Legado Lelong en Antropología Social), Mondes Américains - UMR 8168, Centre de Recherches sur le Brésil Contemporain (54 bd Raspail, 75006 Paris). E-mail: elisecapredon@gmail.com 
seconde moitié du XXème siècle, plusieurs mouvements évangéliques indigènes ont éclos dans l'aire amazonienne, sous l'influence de missionnaires étrangers. L'article explore ce phénomène à partir de l'étude du cas des Baniwa, un groupe de l'Amazonie brésilienne dont les membres ont créé leurs propres Églises. En analysant la trajectoire de ce mouvement religieux, il montre que sa rencontre avec les Églises évangéliques nationales favorise actuellement son institutionnalisation et son articulation à des mouvements similaires, à l'échelle pan-ethnique et transnationale.

Mots-clés : Amazonie, Brésil, Baniwa, mouvements évangéliques, Églises indigènes, institutionnalisation

\title{
The encounter of indigenous evangelical churches with "national" churches and their political-religious repercussions en the upper Río Negro (Amazonas, Brazil)
}

\begin{abstract}
The anthropological studies that address the relationships between native people and Christianity often underline the ephemeral nature of Amerindian conversions. However, since the second half of the twentieth century, several indigenous evangelical movements have emerged in the Amazonian area under the influence of foreign missionaries. This article explores this phenomenon through the case study of the Baniwa, a group in the Brazilian Amazon whose members have created their own Churches. By analyzing the trajectory of this religious movement, I show that its encounter with the national evangelical churches is currently fostering its institutionalization and its articulation with similar movements, at a pan-ethnic and transnational level.
\end{abstract}

Keywords: Amazonia, Brazil, Baniwa, evangelical movements, Indigenous Churches, institutionalization

\section{INTRODUCCIÓN}

Desde los años 1990, varios estudios etnográficos han abordado las tentativas de evangelización de los grupos indígenas amazónicos de Brasil por parte de misioneros evangélicos (Pollock, 1993; Vilaça, 1996; 2002; 2008; 2016; Wright, ed., 1999; ed., 2004; Montero, ed., 2006; Vilaça \& Wright, eds., 2009; entre otros). Al examinar las modalidades de interpretación y de apropiación —o de rechazo- del mensaje cristiano por los indígenas, muchos subrayan las dificultades de los misioneros para suscitar conversiones perennes ${ }^{1}$. Sin embargo, entre los predicadores norteamericanos y europeos que penetraron en la

1 Véanse por ejemplo, Pollock (1993), Vilaça (1996; 2002; 2008; 2016), Lauriola (2004) y Capiberibe (2009: 249) para casos brasileños o Gow (2006) para un caso peruano. 
Amazonía brasileña en busca de pueblos indígenas «no alcanzados» — es decir, no evangelizados - para llevarles la «palabra de Dios», algunos consiguieron difundir sus ideas e inspirar la creación de Iglesias2 locales. Ahora bien, poco se sabe sobre la formación de estas Iglesias y sobre su destino en la actualidad. En un contexto de urbanización de la población indígena ${ }^{3}$ y de expansión de los movimientos evangélicos nacionales ${ }^{4}$, ¿qué sucede con las congregaciones indígenas que nacieron bajo la influencia de estos misioneros extranjeros? ¿Qué ocurre cuando los convertidos nativos se encuentran con una nueva ola de evangelistas oriundos esta vez de su país? ¿Empiezan los «creyentes»5 indígenas a seguir a los nuevos predicadores o reivindican la especificidad de sus prácticas cristianas?

En este trabajo proponemos contestar a estas preguntas a partir del estudio de caso de los baniwa, un grupo de lengua arawak de la Amazonía brasileña. Establecidos en la región pluriétnica del Alto Río Negro, los baniwa se convirtieron en su mayoría al cristianismo evangélico a mediados del siglo XX, bajo la influencia de una misionera estadounidense llamada Sophie Muller. No solo se apropiaron de su mensaje, sino que fundaron sus propias Iglesias, en las cuales celebran, desde entonces, cultos y ceremonias en su idioma. A partir de los años 1990, algunos baniwa empezaron a migrar hacia la capital regional, São Gabriel da Cachoeira, una pequeña ciudad donde las denominaciones evangélicas venían multiplicándose. Apoyándonos en datos etnográficos recogidos durante investigaciones realizadas con los baniwa entre 2008 y 20176, intentaremos mostrar que en vez de debilitar al movimiento evangélico indígena, el encuentro de sus representantes con las nuevas Iglesias de la ciudad favoreció su consolidación y su institucionalización? A modo de conclusión, esbozaremos una comparación entre este fenómeno y el desarrollo de movimientos evangélicos indígenas en otros países sudamericanos, especialmente en Perú8.

2 Usaré la palabra «lglesia» con mayúscula para referirme a la institución e «iglesia» con minúscula para designar el lugar de culto.

3 La población indígena urbana en Brasil fluctuó bastante en las últimas décadas pues, según los datos del Instituto Brasileño de Geografía y Estadística (IBGE), el porcentaje era de 24,1\% en 1991, 52,2\% en 2000 y 36,2 \% en 2010 (IBGE, s. f.). Aun así podemos considerar que hubo un crecimiento de la presencia indígena en las ciudades entre 1991 y 2010.

4 El porcentaje de evangélicos en la población brasileña pasó de 5,2\% en 1970 a 22,2\% en 2010 (IBGE, 2012a: 89-92).

5 Crentes en portugués, sinónimo de evangélicos.

6 Fueron cuatro investigaciones que representan 18 meses de trabajo de campo. Los datos fueron colectados principalmente con los baniwa que viven en la ciudad de São Gabriel da Cachoeira y en pueblos periurbanos.

7 Este artículo se focaliza en una etapa específica de la formación del movimiento evangélico baniwa, un proceso más amplio que analizo en otro trabajo (Capredon, 2018).

8 En 2017, la obtención de la beca posdoctoral del Legs Lelong me permitió realizar una investigación exploratoria de un mes y medio en la Amazonía peruana para estudiar los movimientos evangélicos indígenas de esta zona. 


\section{EL MOVIMIENTO EVANGÉLICO INDÍGENA DEL RÍO IÇANA}

Los baniwa, que forman en Brasil una población de aproximadamente 6400 personas 9 , viven en su mayoría en «comunidades» 10 diseminadas en la cuenca del río Içana, un afluente del río Negro. A diferencia de los otros grupos regionales, en particular los pueblos de lengua tukano del Vaupés —otro afluente del río Negro-, tuvieron históricamente pocos contactos con los misioneros católicos. Comenzaron a seguir principios cristianos con la llegada de Sophie Muller, una evangelista inicialmente afiliada a la New Tribes Mission que promovía valores y prácticas de origen protestante. Mujer frugal, estricta y perseverante, Sophie Muller ya había trabajado entre los curripaco de Colombia, un pueblo vecino de los baniwa, antes de entrar en el territorio brasileño en 1948. Durante su primer viaje al río Içana, se empeñó en aprender el baniwa, en traducir pasajes de la Biblia a este idioma y en alfabetizar a sus anfitriones para que pudieran leer el texto sagrado. En su segundo viaje, su discurso se volvió más ofensivo y empezó a combatir con ardor todos los usos relacionados con el chamanismo, denominado localmente pajelança. Exigió que los chamanes destruyeran sus instrumentos y proscribió los rituales de iniciación y las grandes fiestas de intercambio, los podáali. Prohibió también el consumo de tabaco, plantas psicotrópicas y bebidas alcohólicas — en particular el caxiri, una bebida fermentada a base de mandioca-, elementos que ocupaban un lugar central en la vida social y ritual de los indígenas de la región. En cambio, instauró un denso calendario litúrgico que incluía, además de cultos y lecturas bíblicas cotidianas, grandes ceremonias regulares. Incentivó el uso de la lengua vernácula y valorizó la vida «comunitaria»11 de los indígenas. Predicó la «palabra de Dios» en la región del Içana hasta 1953, fecha en la que regresó a Colombia huyendo de las autoridades brasileñas que desaprobaban su trabajo (Wright, 1999: 177). Después de su partida, siguió enviando folletos con instrucciones a sus discípulos, en particular a los «ancianos» (anciãos), los líderes evangélicos que ella había designado y formado. Algunos otros misioneros le sucedieron más tarde, pero ninguno llegó a ejercer la misma influencia que ella.

Por supuesto, la adhesión de los baniwa al modo de vida que Sophie Muller enseñaba no se debe únicamente a su talento de predicadora. Los motivos por los cuales la mayoría de los miembros del grupo optaron por volverse «creyentes» son variados y complejos. Uno de los principales tiene que ver con la situación de

9 Según el Sistema de Informação da Atenção à Saúde Indígena, Secretaria Especial de Saúde Indígena, Ministerio da Saúde (SIASI/SESAI/MS, 2013).

10 Introducido por los misioneros católicos — quienes se referían inicialmente a las «Comunidades Eclesiales de Base», un modelo de organización social y religiosa definido por el Concilio Vaticano II-, el término designa actualmente los asentamientos indígenas en el Alto Río Negro.

11 Entendemos por «comunitaria» un modo de vida en pueblos pequeños donde muchas tareas son realizadas colectivamente y donde los habitantes comparten sus comidas diariamente. También la noción de conviviality, según Overing \& Passes (eds., 2000), remite a una forma de vivir basada —entre otras cosas - en la importancia de los lazos de parentesco, la comensalidad y la solidaridad. Sophie Muller consideraba que «[L]a vida indígena, eminentemente comunitaria, es lo que Dios quiere» (Comisión Matallana citada en Stoll, 1982: 171). 
crisis que el grupo experimentaba en la época. La llegada de la misionera coincide con el «régimen extractivista», un periodo de intensa explotación de la mano de obra indígena por parte de comerciantes en busca de recursos forestales (Wright, 1999). Sometidos a estos «patrones» que los mantenían a su servicio a través del sistema de habilitación12, muchos indígenas aspiraban a cambiar de modo de existencia. Al incitarlos a liberarse de estos lazos de dependencia para volver a vivir en sus comunidades y garantizar que Dios supliría sus necesidades si respetaban sus prescripciones, Sophie Muller ofrecía de cierta forma una alternativa a esta situación de opresión.

Esta adhesión tampoco fue unánime: en el río Aiari, un afluente del Içana, la presencia de poderosos chamanes contuvo el avance de la nueva religión o dificultó su arraigo (Wright, 1999: 199, 201). Las familias que nunca aceptaron los principios evangélicos y las que desistieron de ser «creyentes» forman desde entonces una minoría políticamente marginada cuyos miembros son genéricamente considerados «católicos» ${ }^{13}$.

No obstante, no nos detendremos aquí en el episodio de la conversión, pues ya está bastante bien documentado14. Trataremos, más bien, de reconstituir la formación de las Iglesias nativas en las décadas siguientes y de precisar algunas de sus características.

Si bien el proceso de adhesión de los baniwa al cristianismo evangélico no fue lineal ni homogéneo, la nueva religión se difundió progresivamente en el grupo hasta representar la forma religiosa dominante ${ }^{15}$. Conforme a las recomendaciones de Sophie Muller, los convertidos erigieron templos — hechos de barro con techos de hojas de palmeras - para celebrar sus cultos (fig. 1).

Realizados en lengua nativa, los cultos se componían de «alabanzas» cantadas, oraciones, lecturas del libro sagrado y memorización de versículos (Muller, 2013 [1988]: 81). Los líderes que los conducían, los «ancianos», enfatizaban sobre todo las reglas de conducta que los miembros de la Iglesia16 tenían que seguir: no beber, no fumar, no frecuentar las fiestas profanas, no cometer adulterio, respetar a los mayores, etc. De hecho, a diferencia de los protestantes en general, que suelen asociar la conversión a la construcción de una relación íntima con el dios cristiano, los baniwa la perciben más bien —al igual que otros grupos indígenas

12 Aviamento en portugués, sistema de dominación por el endeudamiento. De manera simplificada, consiste en que un comerciante adelante un salario o mercancía a trabajadores a quienes en seguida obliga a trabajar a su servicio hasta el pago completo de la deuda, constantemente diferido.

13 En el Alto Río Negro, el término es ambiguo: puede designar a los católicos practicantes o a los adeptos de un catolicismo popular centrado en las fiestas de santos, pero también a las personas que mantienen prácticas chamánicas —o que combinan estas diferentes opciones-.

14 Véase, en particular, Wright (1999). Para una síntesis de los datos disponibles sobre la conversión de los baniwa y sus interpretaciones, véase Capredon (2016: 143-171).

15 No existen estadísticas sobre las afiliaciones religiosas de los baniwa, pero Wright estima que el $80 \%$ de los miembros del grupo son evangélicos (Wright, 2013: 5).

16 En la mayoría de los casos, los miembros de la Iglesia se confundían con los de la comunidad pues no se toleraban disidentes en los pueblos evangélicos. 


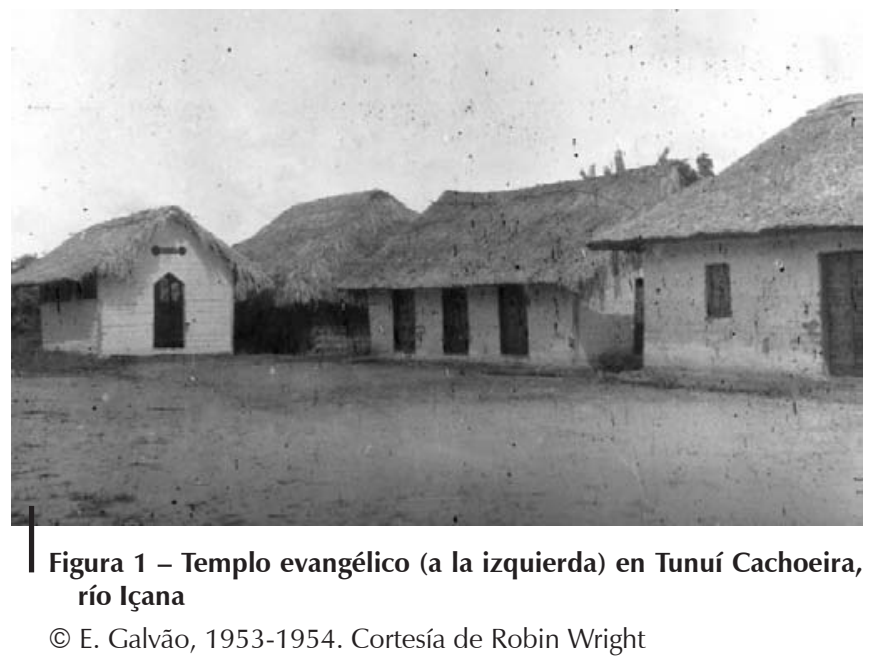

amazónicos17- como un cambio de comportamiento destinado a garantizar o restaurar una vida comunitaria armoniosa. La importancia que atribuyen a la sociabilidad —más que a la salvación individual— se refleja en el apego de los creyentes a los grandes encuentros que sustituyeron los podáali: las Santas Cenas y las Conferencias. Organizadas una vez al mes, las Santas Cenas reúnen cuatro o cinco comunidades de un mismo trecho de río para celebrar la eucaristía. Los pueblos se turnan para acoger el evento. Las Conferencias funcionan de la misma manera, pero movilizan a centenares de personas procedentes de decenas de asentamientos dispersos en la cuenca del río Içana y en zonas de Colombia y Venezuela evangelizadas por Sophie Muller. Programadas con mucha antelación, estas ceremonias de gran envergadura exaltan la cordialidad, la hospitalidad y la solidaridad, pero también el autocontrol y la disciplina a través de una serie ininterrumpida de actividades colectivas (cultos, torneos deportivos y comidas abundantes) regidas por reglas rigurosas.

La primera Conferencia parece haber sido realizada en 1956, diez años después de la llegada de Sophie Muller a la Amazonía (Xavier, 2013: 464). Unos diez años más tarde, en 1965, la misionera calculaba que se organizaban nada menos que veintiocho Conferencias por semestre (Muller, 2013 [1988]: 183). Resaltaba también la creación de 200 iglesias, únicamente del lado colombiano (Muller, 2013 [1988]: 184).

Así, durante aproximadamente treinta años, las Iglesias indígenas, bautizadas por Sophie Muller como «lglesias Bíblicas Unidas», fueron esparciéndose, y la afiliación evangélica se volvió para los baniwa un signo distintivo con respecto a las familias que mantenían prácticas chamánicas y a los otros pueblos indígenas del Alto Río Negro, considerados católicos.

17 Véase, por ejemplo, Vilaça (1996). 
A partir de los años 1990, esta configuración religiosa empezó, no obstante, a cambiar debido al fallecimiento de la misionera americana ${ }^{18}$ y al encuentro de los baniwa con nuevos actores religiosos.

\section{LA LLEGADA DE LAS NUEVAS IGLESIAS Y LAS MIGRACIONES INDÍGENAS HACIA LA CIUDAD}

A diferencia de Sophie Muller y, de forma más general, de los primeros divulgadores del protestantismo en la Amazonía brasileña, que eran en su mayoría norteamericanos y europeos (Boyer, 2008: 25), estos nuevos actores religiosos no eran extranjeros, sino oriundos de otras partes de Brasil. Por lo tanto, los Ilamaremos aquí evangelistas o pastores «nacionales». Los evangelistas nacionales comenzaron a llegar al Alto Río Negro a finales de los años 1970, cuando la capital regional, São Gabriel da Cachoeira, se volvió una ciudad.

Esta localidad, de unas pocas centenas de habitantes durante la primera mitad del siglo XX19, creció en los años 1970 cuando el Gobierno federal, que promovía el desarrollo económico de la Amazonía, envió allí a un contingente de militares encargados de construir infraestructuras. En la estela de los militares, Ilegaron obreros y otros trabajadores en busca de empleo, lo que provocó un rápido aumento de la población. Ahora bien, entre los recién llegados, algunos no solo participaron en las obras públicas, sino que también implantaron Iglesias evangélicas, acabando así con la hegemonía de la Iglesia católica presente en la ciudad a través de una poderosa misión salesiana20. Ellos constituían la encarnación local del desarrollo de los movimientos evangélicos a nivel nacional (Freston, 1996) y continental (Stoll, 1990; Bastian, 1994)21. En la Amazonía, esta expansión fue favorecida por la gran movilidad de la población a nivel regional, que está ligada a factores ambientales y a la apertura de los frentes pioneros (Boyer, 2008: 29). Es menos el fruto de la acción de profesionales que el de una multitud de evangelistas anónimos que improvisaron su misión por no tener alternativas económicas o de ascensión social (Boyer, 2008: 30). Así, los fundadores de las primeras Iglesias evangélicas

18 Por aquel entonces, Sophie Muller ya había perdido una parte de su influencia, por lo menos del lado colombiano. De hecho, Stoll indica que «para los años setenta, el imperio de Muller estaba desmoronándose» (Stoll, 1982: 171).

19 Galvão, quien recorrió el Alto Río Negro entre 1951 y 1955, estima que la población de São Gabriel da Cachoeira era entonces «inferior a 600 habitantes» (Galvão, 1959: 2).

20 Varias órdenes religiosas se sucedieron en la región durante el periodo colonial, pero las dificultades que tuvieron para implantar misiones duraderas limitaron su impacto. Los salesianos, que llegaron al principio del siglo XX, gozaban de recursos importantes. Al construir internados en varios puntos estratégicos de la región, lograron provocar cambios mucho más profundos en las costumbres indígenas.

21 Aquí, la noción de «movimientos evangélicos» incluye los movimientos pentecostales, que atribuyen una importancia central a las manifestaciones del Espírito Santo. En São Gabriel da Cachoeira, muchas de las nuevas Iglesias urbanas son pentecostales, pero no todas, así que preferí conservar la categoría más amplia de movimiento «evangélico». 
de São Gabriel da Cachoeira son, generalmente, migrantes de origen humilde que vienen de otras regiones brasileñas, a menudo de otras regiones amazónicas o del Nordeste. Por ejemplo, la pareja que implantó la primera Asamblea de Dios22 en el centro urbano (fig. 2) estaba formada por una evangelista del Piauí, un estado del Nordeste, y un pastor de Rondônia, un estado amazónico. Aún siendo titulares del estatuto de misioneros no recibían apoyo de su Iglesia, pues la mujer señaló en una entrevista concedida al historiador aficionado Edmar César23, que al llegar tenían «poco dinero» y ninguno de los dos tenía empleo. Comenzó lavando ropa y preparando mocotó, un plato popular a base de pedazos de carne baratos, para «sobrevivir y sustentar el trabajo de Dios» (Maria Albina Rodrigues da Silva citada en César, 2015 [2007]: 102-103).

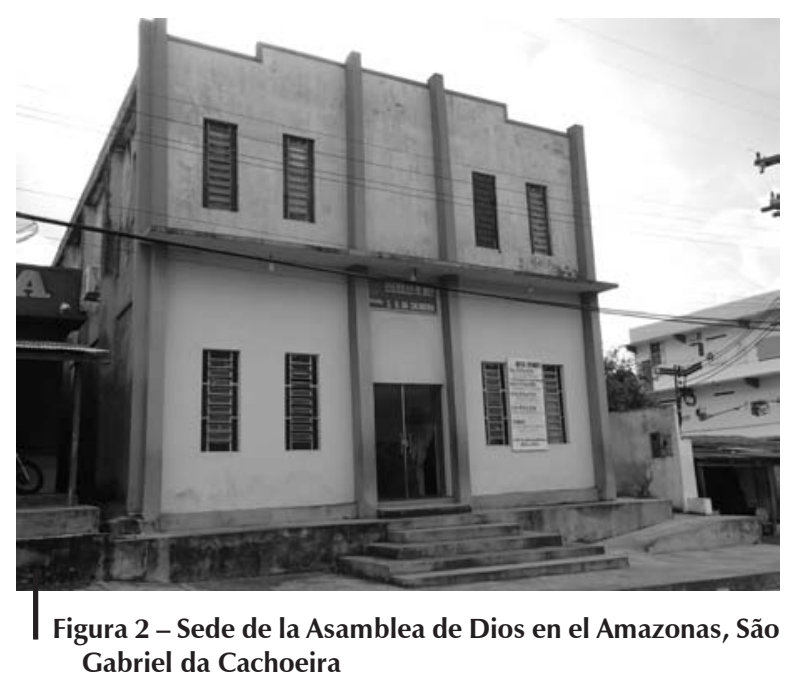

(C) E. Capredon, 2017

El éxito de estos nuevos prosélitos no fue inmediato; no obstante, en las últimas décadas del siglo XX, el movimiento evangélico fue creciendo en São Gabriel da Cachoeira hasta alcanzar una decena de Iglesias en 200824. Si bien los pastores de estas denominaciones no se focalizaban específicamente en la evangelización de los indígenas, como era el caso de sus predecesores extranjeros, la afluencia de público indígena a sus templos fue aumentando a medida que las migraciones de la población rural hacia la ciudad se incrementaban.

22 La Asamblea de Dios (Assembléia de Deus) es actualmente la mayor Iglesia evangélica de Brasil en términos de número de adeptos (IBGE, 2012a).

${ }^{23}$ Edmar César es un militar que trabajó algunos años en São Gabriel da Cachoeira. Escribió dos libros sobre el municipio, ricos en datos sobre la historia reciente de la ciudad.

${ }^{24}$ Censo efectuado en 2008 durante mi primera investigación etnográfica en São Gabriel da Cachoeira. 
Los habitantes de la zona rural del municipio de São Gabriel da Cachoeira, los cuales son casi exclusivamente indígenas 25 , empezaron a converger hacia la capital regional en los años 1980. La mayoría buscaba un acceso a la educación escolar26, a empleos remunerados y a servicios de salud (Instituto Socioambiental \& Federación de las Organizaciones Indígenas del río Negro [ISA/FOIRN], 2005). Los baniwa, que Sophie Muller había exhortado a mantenerse lejos de los «blancos»27 (Stoll, 1982: 171), se agregaron a este flujo migratorio un poco más tarde, en los años 1990, pero sus desplazamientos son similares a los otros grupos indígenas: no consisten en migraciones definitivas a São Gabriel da Cachoeira, sino en trayectos a través de los cuales se acercan al centro urbano sin dejar de mantener una chacra y, a veces, una casa en su comunidad de origen. Al dirigirse hacia la ciudad, muchos se instalan en su periferia y fundan pueblos periurbanos. Es así frecuente que una parte de la familia, que incluye habitualmente a los niños y jóvenes escolarizados, viva en la ciudad, mientras que la otra reside en una comunidad periurbana o rural. Este doble o triple anclaje va generalmente acompañado de una gran movilidad de los miembros de la familia que circulan entre los diferentes espacios y de un uso complementario de los recursos económicos disponibles en cada uno de ellos (Eloy \& Lasmar, 2011).

Entre los baniwa que se instalaron en São Gabriel da Cachoeira o que crearon nuevos pueblos en su periferia, muchos fueron visitados por pastores blancos que anhelaban ampliar sus «rebaños». A continuación, veremos cómo reaccionaron los que ya eran evangélicos.

\section{DE LAS IGLESIAS DE LOS BLANCOS A LAS IGLESIAS INDÍGENAS URBANAS}

Frente a la proliferación de las Iglesias «nacionales», cuyo número alcanzó recientemente cerca de veinte denominaciones ${ }^{28}$ —entre las cuales algunas poseen varios templos-, los creyentes indígenas adoptaron dos actitudes. Al principio fueron seducidos por estas nuevas Iglesias. Las percibían como lugares donde se enseñaba un mensaje próximo al de Sophie Muller y, sobre todo, como espacios de inclusión social donde podían tener acceso a servicios que les hacían falta. De hecho, las Iglesias de la ciudad no solo realizan cultos casi todos los días, sino que llevan a cabo muchas acciones sociales y caritativas. La mayoría propone una ayuda material a las familias más necesitadas (distribución de productos alimentarios básicos, venta de ropa de segunda mano, etc.) y organiza actividades

25 En la zona rural del municipio de São Gabriel da Cachoeira, el 95,5\% de la población es indígena (IBGE, 2012b: 17).

26 El cierre de cinco internados salesianos en los años 1980 llevó a muchas familias a instalarse en la ciudad para que sus hijos pudieran seguir estudiando.

27 En el Alto Río Negro, el término designa a todos los no indígenas, independientemente del color de su piel.

${ }^{28}$ Censo efectuado en São Gabriel da Cachoeira en junio y julio de 2017. 
pedagógicas para los niños y jóvenes. Las más prósperas también ofrecen servicios de salud y usan, durante los cultos, equipamientos audiovisuales sofisticados (micrófono, amplificador, computador, videoproyector, etc.) que los fieles, en particular los más jóvenes, aprecian y pueden así aprender a manejar. Lejos de ser anecdóticos, estos aspectos son bastante valorizados en un contexto en que las familias indígenas tienen dificultades para garantizar su subsistencia y en el que más de la mitad de la población urbana tiene menos de 25 años 29.

Sin embargo, en estas Iglesias «nacionales», los creyentes indígenas suelen ser excluidos de las funciones litúrgicas. Ocupan usualmente el rango de simples fieles, siendo así descalificados como oficiantes rituales. Ciertos líderes evangélicos indígenas relatan que cuando se presentan como «ancianos» de las «lglesias Bíblicas Unidas», los pastores blancos se burlan de ellos porque no poseen título de pastor y porque nadie conoce el nombre de su Iglesia ${ }^{30}$. Frente a esta situación, algunos de ellos decidieron fundar sus propias denominaciones en São Gabriel da Cachoeira.

El primero, el pastor Luis, que no es baniwa, sino baré31, creó al final de los años 1990 un Instituto Bíblico con la ayuda de pastores no indígenas. Desde que sus colaboradores lo dejaron, él mantiene solo este establecimiento, donde pretende formar líderes evangélicos indígenas. Para él, se trata de preservar la orientación doctrinal de los primeros misioneros que trabajaron en la región, de «ser independiente» y de «salir del paternalismo».

El segundo es el pastor Silvério, un hombre baniwa que fundó, a comienzos de los años 2000, la primera «Iglesia Evangélica Indígena» de la ciudad, donde los cultos se realizan en parte en lengua nativa. Su iniciativa fue un éxito, pues en 2010 abrió un segundo templo (fig. 3) que, por su tamaño, rivaliza con las más prósperas Iglesias urbanas.

El tercero es el evangelista Joãozinho, quien tras haber estudiado en el Instituto Bíblico del pastor Luis, implantó en la capital regional una «lglesia Bíblica Unida» hacia el año 2010. El templo de esta Iglesia pasó de lucir inicialmente una construcción rudimentaria a exhibir una estructura robusta, con paredes de cemento y techo de zinc. El objetivo de Joãozinho consiste en mantener la herencia de Sophie Muller, «reunir a los hermanos del interior», es decir, a los creyentes indígenas de la zona rural y, sobre todo, conseguir «títulos». De hecho, el pastor lamenta que los primeros misioneros que recorrieron el Içana no hayan entregado a sus discípulos títulos de pastor y de diácono reconocidos en la ciudad.

29 Cálculo efectuado a partir de los datos sobre grupos de edad y situación domiciliar de la población de São Gabriel da Cachoeira (censo de 2010), disponibles en el sitio web del IBGE (IBGE, s. f.).

30 Véase, por ejemplo, el testimonio de un «anciano» curripaco que se sintió humillado en una reunión de pastores en Manaus porque no tenía «tarjeta» de pastor (Xavier, 2013: 418).

31 Los baré, que ocupan el alto curso del río Negro (donde desemboca el río Içana), son un pueblo vecino de los baniwa. Como han dejado de hablar su lengua, que pertenecía a la familia arawak, fueron durante mucho tiempo considerados indígenas aculturados. Sin embargo, con el desarrollo del movimiento indígena, volvieron a ser reconocidos como un grupo étnico. En la época de Sophie Muller, algunos de ellos se convirtieron al cristianismo evangélico. 


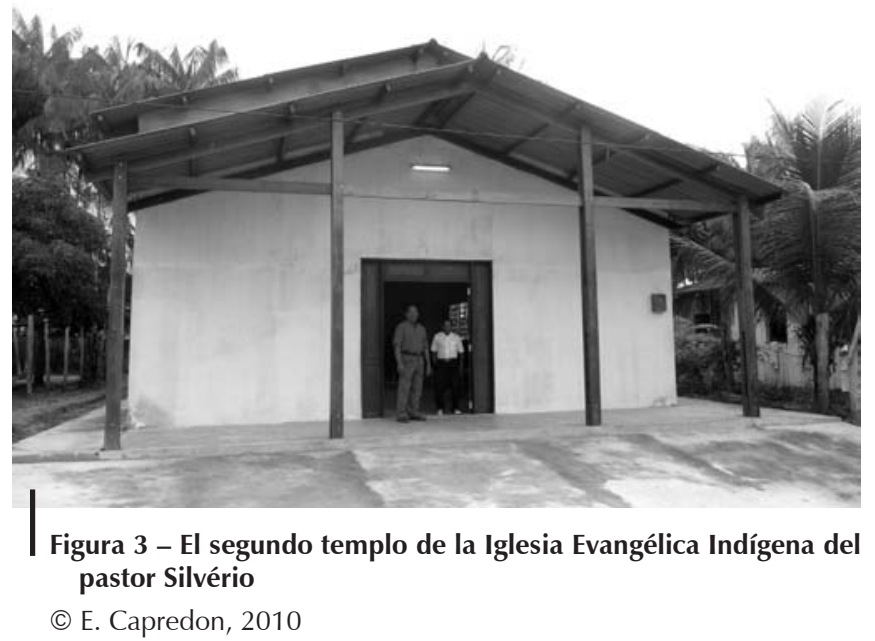

Finalmente, durante mi última investigación de campo, en 2017, hallé una cuarta Iglesia indígena que había sido creada dos años antes. Denominada «Congregación Batista Bíblica Fuente de Bendiciones», está dirigida también por un pastor baniwa. A estas Iglesias indígenas de São Gabriel podemos añadir las que fueron erigidas en comunidades periurbanas. Existen por lo menos dos32, encabezadas por líderes evangélicos nativos. Sus miembros organizan, como en la región del Içana, Santas Cenas y Conferencias a las cuales acuden tanto los creyentes nativos de la zona rural como los de São Gabriel da Cachoeira. Estas Iglesias periurbanas aseguran así una conexión entre las congregaciones indígenas urbanas y las del río Içana.

Desde el inicio del siglo XXI, surgieron varias Iglesias indígenas en São Gabriel da Cachoeira y en su periferia. Al igual que las Iglesias fundadas en el Içana, estas denominaciones no tienen poder centralizado, pero sí comparten una historia y valores comunes. Aunque imitan ciertos aspectos de las Iglesias de los blancos (arquitectura de los templos, vestimenta de los pastores, a veces uso de material audiovisual), se distinguen de ellas por el discurso de sus dirigentes — que no está centrado en la fe individual ni en la teología, sino en principios éticos-, por el uso de las lenguas indígenas, por ciertas prácticas rituales (saludos colectivos para abrir y cerrar las ceremonias, confesión pública, división de los fieles por género y edad en el espacio del templo, nombramiento, durante las Conferencias, de «policías» que vigilan a los participantes) y por detalles litúrgicos (comunión celebrada con pedazos de galleta de mandioca y jugo de açaí33 o uso de cestos

32 Existen muchas Iglesias evangélicas en las comunidades periurbanas, pero la mayoría son «sucursales» de Iglesias de São Gabriel da Cachoeira dirigidas por pastores blancos. Las dos Iglesias a las cuales nos referimos fueron en cambio fundadas por un baniwa y un curripaco evangélicos oriundos del Içana. Una de ellas lleva el nombre de «Iglesia Bíblica Unida».

33 Fruto de una palmera (Euterpe precatoria o Euterpe oleracea Mart.), cuyo jugo es de un color morado similar al del vino. 
artesanales para recoger el diezmo, por ejemplo). Sus dirigentes buscan ahora ser reconocidos como oficiantes rituales legítimos, al igual que los pastores blancos. Como veremos, esta búsqueda de legitimidad ocasiona una formalización de las actividades religiosas.

\section{LA INSTITUCIONALIZACIÓN DEL MOVIMIENTO EVANGÉLICO BANIWA}

La búsqueda de reconocimiento de los líderes evangélicos baniwa no es un fenómeno aislado, se inscribe en el marco más amplio de las luchas de los pueblos indígenas para hacer valer sus derechos dentro de la sociedad nacional. En el Alto Río Negro, el movimiento indígena nació a finales de los años 1970 impulsado por líderes nativos que, con la ayuda de militantes indigenistas, reclamaban la demarcación de sus tierras. Dio lugar a la creación de decenas de asociaciones locales que, en 1987, se reunieron para formar la Federación de las Organizaciones Indígenas del Río Negro (FOIRN), que se convirtió en una de las más poderosas organizaciones indígenas de la Amazonía. Tras haber obtenido la homologación de una extensa Tierra Indígena en 1998, los líderes de este movimiento ampliaron sus reivindicaciones a otras áreas, como la educación, la salud o la cultura. En todas estas esferas se trata de dar término a las diversas formas de dominación históricamente ejercidas por los blancos y de reconquistar cierta autonomía. Aunque los líderes evangélicos indígenas no participan directamente en estas movilizaciones, su voluntad de emanciparse de las autoridades religiosas blancas refleja en parte las aspiraciones de sus homólogos políticos.

Para afirmarse como especialistas rituales competentes y ganar visibilidad en la escena religiosa regional, desarrollan diversas estrategias.

En primer lugar, abandonan el título de «anciano», no reconocido fuera del Içana, en favor del de «paston», y se esfuerzan por legalizar sus Iglesias. En Brasil, la legalización de una organización religiosa se hace a través de su registro en el «Cadastro Nacional da Pessoa Jurídica»(CNPJ), que depende del Ministerio de Hacienda. Este proceso requiere la redacción de un acta de fundación, la especificación de los recursos económicos de la entidad religiosa, el mantenimiento de una contabilidad y la elaboración del «estatuto» de la Iglesia, que exige a su vez la designación de un consejo administrativo, la definición de una orientación doctrinal y el establecimiento de los derechos y deberes de los miembros. En suma, implica la oficialización y normalización de principios y prácticas que eran antes más informales y flexibles. Para los baniwa, que no están acostumbrados a realizar trámites burocráticos, este proceso jurídico representa una operación compleja. Supone también gastos importantes, pues si el Estado no cobra por la emisión del CNPJ, el registro, que se hace en un Cartório (oficina notarial), es de costo elevado ${ }^{34}$.

34 Las sumas gastadas varían, pero pueden alcanzar los 1000 reais, un valor superior al salario mínimo (de aproximadamente 900 reais). Conseguir tal suma requiere meses de ahorro para un pastor indígena y su congregación. 
Estos obstáculos no desaniman a los líderes evangélicos nativos, pues la obtención de un CNPJ (el número que comprueba el registro jurídico de la Iglesia) les proporciona credibilidad frente a los pastores blancos y les autoriza a recibir donaciones financieras. Para Alcir, un creyente baniwa que ayudó al pastor Joãozinho a legalizar su Iglesia, el CNPJ permite ante todo emitir facturas y, por lo tanto, percibir ayudas económicas de otras Iglesias e instituciones. Esto puede parecer paradójico, pues si los pastores nativos aspiran a emanciparse de las autoridades religiosas blancas, ¿por qué buscarían su apoyo? Sin embargo, esta actitud tiene sentido a nivel local, por dos razones: en primer lugar, los pastores indígenas no suelen recibir donaciones de sus competidores directos, sino que privilegian alianzas con Iglesias «de fuera», es decir, de otras regiones de Brasil o del extranjero; y luego, las ayudas financieras no provienen únicamente de instituciones religiosas. Como explica Alcir, el hecho de poseer un CNPJ permite solicitar subvenciones de la municipalidad, de los concejales o de otras entidades públicas; hasta permitiría pedir apoyo logístico de la policía para regular el tráfico cuando se organizan grandes eventos.

En segundo lugar, los líderes evangélicos baniwa intentan federar las Iglesias indígenas del Alto Río Negro para poder competir con las Iglesias que forman parte de Convenciones 35 . Las Convenciones son organismos que agrupan Iglesias que pertenecen a una misma denominación o que promueven una misma orientación doctrinal. Tienen como vocación defender los intereses de sus miembros a nivel nacional y juegan un papel de asistencia y capacitación. Alcir señala que en las Iglesias convencionadas, la centralización parcial de los recursos permite asegurar un sueldo regular a los pastores ${ }^{36}$, un privilegio del cual los líderes evangélicos indígenas quisieran poder disfrutar. En el Alto Río Negro, la primera tentativa de federación de las Iglesias indígenas tuvo lugar en 2001 cuando algunos líderes evangélicos baniwa, entre los cuales figuraba el pastor Silvério, fundaron, con el apoyo de un pastor coreano37, la Convención de las Iglesias Bíblicas Unidas Indígenas del Río Negro (CIBUIRN). No obstante, esta entidad, destinada a detener la «invasión» de las nuevas denominaciones y a preservar las enseñanzas de los primeros misioneros (César, 2015 [2007]: 107), fue debilitada por desacuerdos internos. Algunos atribuyen su carencia de impacto al intervencionismo de los pastores no indígenas y otros, al exclusivismo de ciertos dirigentes que hubieran decidido aceptar en su seno únicamente las Iglesias que llevaban el nombre de «Bíblicas Unidas».

En cualquier caso, en este contexto, los líderes evangélicos indígenas buscaron alternativas y algunos de ellos optaron por establecer relaciones con una

35 En São Gabriel da Cachoeira, varias Iglesias, como por ejemplo la Adventista, las Asambleas de Dios y las Bautistas, están afiliadas a Convenciones.

36 Según Alcir, en las Iglesias afiliadas a Convenciones, el 30\% del diezmo colectado entre los fieles es enviado a la sede de la Convención para ser redistribuido a los pastores bajo la forma de salarios.

37 El pastor Kim, quien fundó en los años 1990 un instituto bíblico en la periferia de São Gabriel da Cachoeira, el Instituto Bíblico del Alto Río Negro (IBARNE), y una Iglesia Presbiteriana en la ciudad. Es una figura prominente y atípica de la escena religiosa regional. 
organización de envergadura mucho mayor que nació en otra región de Brasil, el Consejo Nacional de Pastores y Líderes Evangélicos Indígenas (CONPLEI).

Creado en 1991, el CONPLEI está actualmente dirigido por el pastor Henrique Terena que, como indica su apellido, pertenece al grupo terena, un pueblo indígena del centro-oeste de Brasil. Su consejo administrativo está formado por líderes evangélicos de varias etnias (terena, macuxi, bakairi y kadiweu) y posee por lo menos tres anclajes geográficos: uno en el Mato Grosso, donde está su sede, uno en la región Sur y otro en la región Norte, en el Amazonas. Su objetivo prioritario consiste en «promover la unión y la confraternización de los pastores y demás líderes evangélicos indígenas» 38 a nivel nacional.

En el Alto Río Negro, la noticia de la existencia del CONPLEI parece haber llegado a principios de los años 200039. En 2006, el pastor Silvério participó por primera vez — tras haber recibido una invitación — en un evento del CONPLEI en el estado de Rondônia y, dos años después, fue nombrado representante del organismo para el Alto Río Negro. En 2011, realizó un «mini-CONPLEl» en una comunidad periurbana, al cual acudieron cerca de 500 personas (Xavier, 2013: 428-429) y, en 2012, fue oficialmente consagrado pastor por Henrique Terena40. Finalmente, en 2017, organizó un congreso regional41 del CONPLEI cerca de São Gabriel da Cachoeira, en un extenso terreno adquirido para la ocasión (fig. 4).

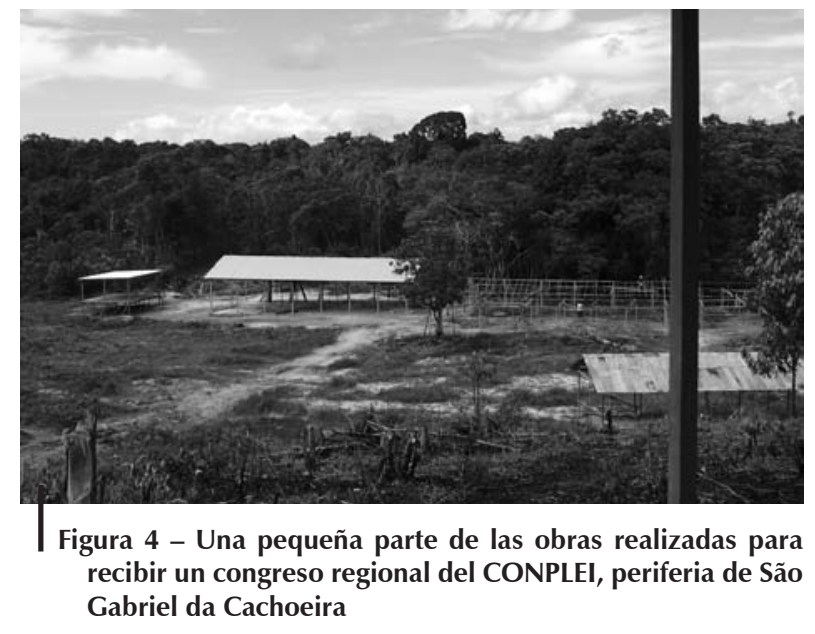

(C) E. Capredon, 2017

${ }^{38}$ Cita del sitio web oficial de la organización (http://www.conplei.org.br/v2/), sección «O que é CONPLEI», consultado el 25 de octubre de 2017.

39 El pastor Silvério afirma que se enteró por primera vez de la existencia del CONPLEl a través de un pastor no indígena, que le mostró un libro que hablaba del organismo.

40 Muchas personas ya lo llamaban «pastor» antes, pero solo tenía el título de «anciano» que había recibido durante una Conferencia.

41 El CONPLEI organiza varios tipos de eventos: congresos nacionales, congresos regionales, encuentros de jóvenes, etc. 
Preparado con dos años de antelación, el encuentro reunió esta vez a unas mil personas, en su mayoría indígenas42.

Para los baniwa, el CONPLEI representa un cambio con respecto a la antigua red de Iglesias de la zona del Içana. Como lo menciona Silverinho, uno de los hijos del pastor Silvério, es una organización más abierta porque federa diversas etnias y no solo los grupos evangelizados por Sophie Muller. Además, los dirigentes del CONPLEI vuelven a valorizar usos culturales indígenas que habían sido reprimidos por la misionera estadounidense y sus discípulos, como las pinturas corporales, las músicas y las danzas nativas. Según el pastor, estos elementos pueden ser recuperados, siempre que sean usados «para alabar al Señor». Su hijo añade que se trata de «traer de vuelta la cultura [...]: nuestras músicas, nuestras danzas, los instrumentos que usábamos, no para rendir culto a los dioses de los antiguos sino para traer esto dentro de la Iglesia» (Pastor Silvério y Silverinho, comunicación personal, 27 de junio de 2017).

Finalmente, la conexión establecida con el CONPLEI suscitó un interés por las actividades de evangelización (Xavier, 2013: 429-430). Seducidos por el discurso de los líderes del organismo sobre la «tercera ola misionera», una expresión que se refiere a la intención de los indígenas de convertirse ellos mismos en divulgadores del mensaje cristiano tras haber sido evangelizados por misioneros extranjeros (primera ola) y nacionales (segunda ola), algunos creyentes baniwa ambicionan ahora llevar a su vez el Evangelio a comunidades o grupos «no alcanzados».

Así, la decisión de ciertos líderes evangélicos baniwa de adherirse al CONPLEI y la participación creciente de creyentes indígenas en los eventos organizados por este organismo en el Alto Río Negro confieren al movimiento evangélico indígena regional una dimensión panétnica y nacional.

\section{CONSIDERACIONES FINALES: ¿HACIA UNA INTERNACIONALIZACIÓN DE LOS MOVIMIENTOS EVANGÉLICOS INDÍGENAS?}

A lo largo de los últimos años, el movimiento evangélico baniwa ha alcanzado una visibilidad importante en la escena religiosa del Alto Río Negro. Frente a la «invasión» de las Iglesias nacionales, los pastores indígenas tomaron medidas para evitar que sus congregaciones fueran «absorbidas» por las nuevas denominaciones. Su deseo de reconocimiento, que los lleva a regularizar sus propias denominaciones, a solicitar financiamientos y a buscar nuevos aliados fuera del Alto Río Negro, favoreció la institucionalización del movimiento evangélico indígena regional que, de manera similar al movimiento indígena, adquirió una dimensión panétnica y nacional. Cabe mencionar que algunos de sus líderes comparan explícitamente el CONPLEI con las movilizaciones políticas indígenas, representadas en la región

42 No presencié el evento, que aconteció en julio de 2017, pero asistí a los preparativos, entrevisté al pastor Silvério y a uno de sus hijos sobre el asunto y seguí la difusión del evento en línea (en sitios web de organizaciones evangélicas y en las redes sociales). 
por la FOIRN. Silverinho, el hijo del pastor Silvério, sostiene, por ejemplo, que el CONPLEI también se dedica a la defensa de los derechos indígenas y lo considera un «movimiento indígena cristiano».

Además de suscitar preguntas estimulantes sobre los posibles puntos comunes entre las dos dinámicas, esta comparación plantea cuestiones sobre el alcance del movimiento evangélico indígena. De hecho, en la medida en que las luchas en favor de los derechos indígenas se convirtieron en una dinámica transnacional (Morin, 1994; Bellier, 2013), a lo largo de las últimas décadas, podemos preguntarnos si las organizaciones evangélicas indígenas podrían estructurarse también a nivel internacional.

Contestar a esta pregunta exigiría un estudio especialmente dedicado al tema, pero ya se pueden mencionar algunos indicios que apuntan en esta dirección. Por una parte, podemos notar que en varios países latinoamericanos existen ahora redes de Iglesias indígenas.

En Argentina, los toba, un pueblo indígena oriundo del Gran Chaco, fundaron sus propias Iglesias en los años 1960, tras haber estado en contacto con misioneros anglicanos, menonitas y pentecostales. Llamadas «lglesias Evangélicas Unidas», estas se organizan a través de «comisiones» locales, regionales y generales. Cada año, celebran una «Convención», un evento que reúne a los representantes de las comisiones y a todos los fieles que desean participar (Ceriani Cernadas \& Citro, 2005; Tamagno, 2007).

En Ecuador, los indígenas evangélicos empezaron a crear asociaciones provinciales a finales de los años 1960. La mayor y más antigua, la Asociación de Indígenas Evangélicos de la Provincia del Chimborazo (AIECH), adquirió autonomía en la administración de las iglesias y personería jurídica en 1967 (Guamán, 2006: 53). En 1980, se unió a seis otras organizaciones provinciales para formar la Federación Ecuatoriana de Indígenas Evangélicos (FEINE) que coordina el movimiento a nivel nacional (Guamán, 2006: 65).

En Perú no hay un equivalente nacional de la FEINE, pero surgieron organizaciones regionales, como la Fraternidad de Asociaciones de Iglesias Evangélicas Nativas de la Amazonía Peruana (FAIENAP). Fundada en 1988, la FAIENAP está implantada en una ciudad de la Amazonía peruana central, Pucallpa. Agrupa quince asociaciones de Iglesias evangélicas de once pueblos indígenas diferentes (achuar, candoshi, junikuin, shawi, kakataibo, machiguenga, qechua, shipibo-conibo, ticuna, wampí y yanesha). Pretende incentivar el desarrollo de la acción misionera en la Amazonía, apoyar la edificación de Iglesias nativas, promover la «confraternidad» entre estas Iglesias, protegerlas contra las «sectas religiosas falsas» y representarlas ante las instituciones públicas o privadas y ante las Iglesias evangélicas nacionales e internacionales —entre otras cosas— ${ }^{43}$. Si su sede está construida en el terreno de una misión extranjera que la apoya, la Misión Suiza, sus representantes afirman

43 La lista completa de los objetivos de la FAIENAP aparece en la sección «Propósitos y fines» del sitio web de la organización (https://faienap.wordpress.com/). 
actuar de forma independiente. Organizan seminarios de capacitación de pastores y misioneros indígenas, así como campañas de evangelización en las diversas regiones amazónicas de donde provienen. A través de este tipo de entidad, los líderes evangélicos de diversas etnias se encuentran, coordinan sus acciones y elaboran proyectos comunes.

Por otra parte, ciertos pastores nativos promueven una unión panamazónica de las Iglesias evangélicas indígenas. En 2009, algunos de ellos, entre los cuales figuraban líderes del CONPLEI de Brasil y de la FAIENAP de Perú, decidieron crear una nueva instancia destinada a federar las organizaciones evangélicas indígenas nacionales, la Red Trans-Amazónica. Esta red, cuyo presidente es por ahora el mismo que el del CONPLEI, el pastor brasileño Henrique Terena, reúne a líderes evangélicos indígenas de varios países: Brasil, Perú, Bolivia, Colombia, Ecuador, Guyana y Paraguay44. Todavía no posee sede, pero sus integrantes se encuentran regularmente. Esto indica que los movimientos evangélicos nativos están intentando articularse a nivel transnacional. Falta ahora esclarecer los objetivos y las modalidades de tal proyecto.

\section{Agradecimientos}

Agradezco a Ana Peña Vellaz y a Esteban Arias Urizar por su valiosa ayuda para corregir este texto en español.

\section{Referencias citadas}

BASTIAN, J.-P., 1994 - Le protestantisme en Amérique Latine. Une aproche socio-historique, 324 pp.; Ginebra: Labor et Fides.

BELLIER, I., 2013 - La reconnaissance internationale des peuples autochtones. In: Peuples autochtones dans le monde. Les enjeux de la reconnaissance (I. Bellier, ed.): 13-37; París: L'Harmattan.

BOYER, V., 2008 - Expansion évangélique et migrations en Amazonie brésilienne. La renaissance des perdants, 232 pp.; París: Institut de Recherche pour le Développement (IRD), Karthala.

CAPIBERIBE, A., 2009 - Nas duas margens do rio. Alteridade e transformações entre os Palikur na fronteira Brasil/Guiana francesa, 425 pp.; Río de janeiro: Universidade Federal do Rio de Janeiro. Tesis de doctorado en Antropología social.

${ }^{44}$ Según los dos informantes peruanos (un líder evangélico shipibo y un misionero «nacional») que describieron el funcionamiento de la Red Trans-Amazónica, esta red debería incluir también una organización venezolana pero la crisis político-económica que afecta el país dificulta la movilización de los indígenas evangélicos de Venezuela. 
CAPREDON, É., 2016 - Les Églises autonomes. Évangélisme, chamanisme et mouvement indigène chez les Baniwa de l'Amazonie brésilienne, 672 pp.; París: École des Hautes Études en Sciences Sociales (EHESS), Universidade Federal do Rio de Janeiro. Tesis de doctorado en Antropología social y Etnología.

CAPREDON, É., 2018 - L'autonomisation des Églises baniwa. Genèse et institutionnalisation d'un mouvement évangélique amérindien. Journal de la Société des Américanistes, 104 (2): 9-32.

CERIANI CERNADAS, C. \& CITRO, S., 2005 - El movimiento del evangelio entre los Toba del Chaco argentino. Una revisión histórica y etnográfica. In: De Indio a Hermano. Pentecostalismo indígena en América Latina (B. Guerrero Jiménez, comp.): 111 170; Iquique: Ediciones El Jote Errante, Campus Universidad Arturo Prat.

CÉSAR, E., 2015 [2007] - São Gabriel da Cachoeira. Sua Saga, Sua História, 430 pp.; Goiânia: Editora Kelps.

ELOY, L. \& LASMAR, C., 2011 - Urbanização e transformação dos sistemas indígenas de manejo de recursos naturais: o caso do alto rio Negro (Brasil). Acta Amazonica, 41 (1): 91-102.

FRESTON, P., 1996 - Breve história do pentecostalismo brasileiro. In: Nem anjos nem demônios. Interpretações sociologicas do Pentecostalismo (A. Antoniazzi, C. Loreto Mariz, I. Sarti, J. Bittencourt Filho, P. Sanchis, P. Freston, R. Valle, R. César Fernandes, W. Gomes, eds.): 67-99; Petropolis, Río de Janeiro: Vozes, Centro de Estatística Religiosa e Investigações Sociais (CERIS).

GALVÃO, E., 1959 - Aculturação indígena no Rio Negro, Belém. Boletim do Museu Paraense Emílio Goeldi, 7: 1-59.

GOW, P., 2006 - Forgetting Conversion. The Summer Institute of Linguistics Mission in the Piro Lived World. In: The Anthropology of Christianity (F. Cannell, ed.): 211-239; Durham: Duke University Press.

GUAMÁN, J., 2006 - FEINE, la organización de los indígenas evangélicos en Ecuador, 108 рp.; Quito: Universidad Andina Simón Bolívar, Abya-Yala, Corporación Editora Nacional. Disponible en https://biblioteca.ibge.gov.br/visualizacao/periodicos/94/ cd_2010_religiao_deficiencia.pdf

INSTITUTO BRASILEÑO DE GEOGRAFÍA Y ESTADÍSTICA (IBGE), 2012a - Censo demográfico 2010. Características gerais da população, religião e pessoas com deficiência, 211 pp.; Río de Janeiro. Disponible en https://biblioteca.ibge.gov.br/ visualizacao/periodicos/94/cd_2010_religiao_deficiencia.pdf (consulta realizada el 28 de septiembre de 2017).

INSTITUTO BRASILEÑO DE GEOGRAFÍA Y ESTADÍSTICA (IBGE), 2012b - Os indígenas no Censo Demográfico 2010. Primeiras considerações com base no quesito cor o raça, 31 pp.; Río de Janeiro. Disponible en https://indigenas.ibge.gov.br/images/ indigenas/estudos/indigena_censo2010.pdf

INSTITUTO BRASILEÑO DE GEOGRAFÍA Y ESTADÍSTICA (IBGE), s. f. - Censo 2010 de São Gabriel da Cachoeira, características da população, população residente, grupo de idade, situação domiciliar. Disponible en https://cidades.ibge.gov.br/brasil/am/saogabriel-da-cachoeira/pesquisa/23/25888?detalhes $=$ true

INSTITUTO BRASILEÑO DE GEOGRAFÍA Y ESTADÍSTICA (IBGE), s. f. - População residente, segundo a situação do domicílio e condição de indígena-Brasil 1991/2010. Disponible en https://indigenas.ibge.gov.br/graficos-e-tabelas-2.html (consulta realizada el 28 de septiembre de 2017). 
El encuentro entre Iglesias evangélicas indígenas y «nacionales» y sus repercusiones político-religiosas

INSTITUTO SOCIOAMBIENTAL \& FEDERACIÓN DE LAS ORGANIZACIONES INDÍGENAS DEL RÍO NEGRO (ISA/FOIRN), 2005 - Levantamento socioeconômico, demográfico e sanitário da cidade de São Gabriel da Cachoeira (AM); São Paulo, São Gabriel de Cachoeira.

LAURIOLA, E. M., 2004 - Entre "Corpo" e "alma". A não-conversão dos Yekuana no Brasil. In: Transformando os Deuses, vol. II. Igrejas evangélicas, pentecostais e neopentecostais entre os povos indígenas no Brasil (R. M. Wright, ed.): 341-375; Campinas: Editora da Unicamp.

MONTERO, P. (ed.), 2006 - Deus da aldeia. Missionários, índios e mediação cultural, 583 pp.; São Paulo: Editora Globo.

MORIN, F., 1994 - De l'Ethnie à l'Autochtonie. Stratégies Politiques Amérindiennes. Caravelle, 63: 161-173.

MULLER, S., 2013 [1988] - Su voz retumba en la selva, 240 pp.; Bogotá: Ediciones Desafío.

OVERING, J. \& PASSES, A. (eds.), 2000 - The Anthropology of Love and Anger. The Aesthetics of Conviviality in Native Amazonia, xiv + 305 pp.; Nueva York: Routledge.

POLLOCK, D. K., 1993 - Conversion and 'Community' in Amazonia. In: Conversion to Christianity. Historical and Anthropological Perspectives on a Great Transformation (R. W. Hefner, ed.): 165-197; Berkeley: University of California Press.

SISTEMA DE INFORMAÇÃO DA ATENÇÃO À SAÚDE INDÍGENA, SECRETARIA ESPECIAL DE SAÚDE INDÍGENA, MINISTERIO DA SAÚDE (SIASI/SESAI/MS), 2013 - Relatório de dados populacionais de 2013 das etnias, por DSEI. Disponible en http:// dw.saude.gov.br/gsid/servlet/mstrWeb?src = mstrWeb.2048001\&evt $=2048001 \&$ sh are $=1 \&$ hiddensections $=$ header $\% 2$ Cpath $\% 2$ CdockLeft $\% 2$ Cfooter \&visMode $=0 \& \mathrm{c}$ urrentViewMedia $=2 \&$ documentID $=5$ DECC34E11E3629D00000080EF2535D4\& Server $=$ SRVBIPDF03\&Port $=0 \&$ Project $=$ DMSIASI_ $4 \&$ (consulta realizada el 7 de marzo de 2019).

STOLL, D., 1982 - Fishers of Men or Founders of Empire? The Wycliffe Bible Translators in Latin America, vii + 344 pp.; London, Cambridge: Zed Press, Cultural Survivor Inc.

STOLL, D., 1990 - Is Latin America Turning Protestant? The Politics of Evangelical Growth, 424 pp.; Berkeley: University of California Press.

TAMAGNO, L., 2007 - Champ religieux et relations de pouvoir. Le pentecôtisme chez les Tobas urbains en Argentine. Anthropologica, 49 (1): 125-135.

VILAÇA, A., 1996 - Cristãos sem fé: alguns aspetos da conversão dos Wari' (Pakaa Nova). Mana. Estudos de Antropologia social, 2 (1): 109-137.

VILAÇA, A., 2002 - Missions et conversions chez les Wari'. Entre protestantisme et catholicisme. L'Homme. Revue française d'anthropologie, 164: 57-79.

VILAÇA, A., 2008 - Conversão, predação e perspectiva. Mana. Estudos de Antropologia social, 14 (1): 173-204.

VILAÇA, A., 2016 - Praying and Preying. Christianity in Indigenous Amazonia, xiv + 316 pp.; Berkeley: University of California Press.

VILAÇA, A. \& WRIGHT, R. M. (eds.), 2009 - Native Christians. Modes and Effects of Christianity among Indigenous Peoples of the Americas, xii + 252 pp.; Farnham: Ashgate.

WRIGHT, R. M., 1999 - O tempo de Sophie: história e cosmologia da conversão baniwa. In: Transformando os Deuses, vol. I. Os múltiplos sentidos da conversão entre os povos indígenas no Brasil (R. M. Wright, ed.): 155-215; Campinas: Editora da Unicamp. 
WRIGHT, R. M. (ed.), 1999 - Transformando os Deuses, vol. I. Os múltiplos sentidos da conversão entre os povos indígenas no Brasil, 547 pp.; Campinas: Editora da Unicamp.

WRIGHT, R. M. (ed.), 2004 - Transformando os Deuses, vol. II. Igrejas evangélicas, pentecostais e neopentecostais entre os povos indígenas no Brasil, 407 pp.; Campinas: Editora da Unicamp.

WRIGHT, R. M., 2013 - Mysteries of the Jaguar Shamans of the Northwest Amazon, vx +387 pp.; Lincoln and London: University of Nebraska Press.

XAVIER, C. L., 2013 - Os Koripako do Alto Içana. Etnografia de um grupo indígena evangélico, 573 pp.; Río de Janeiro: Universidade Federal do Rio de Janeiro. Tesis de doctorado en Antropología social. 